\title{
A survey of specialist trainees in dentistry - current working patterns and career aspirations
}

\author{
The current working patterns and future career aspirations of specialist trainees in dentistry \\ C. S. Drugan, I. G. Chestnutt and J. R. Boyles Br Dent J 2004; 196: 761-765
}

\section{Objectives}

To determine current demographic details of dental specialist registrars in the UK, to examine their current working patterns and ascertain their future career aspirations.

\section{Methods}

A cross-sectional survey, using a self-administered postal questionnaire of all 418 dental specialist registrars (SpRs) in the UK.

\section{Results}

The response rate was 78\%. Of the SpRs who responded, 59\% were male, the majority were aged under $36,54 \%$ were married and over one third had dependants. Orthodontics had the greatest number of SpRs with 141, followed by maxillofacial surgery (70) and restorative dentistry (52). On completion of training, 80\% of SpRs intended to work full time. Significantly more women intended to work part-time. Only a fifth of SpRs said they would consider an academic appointment compared with 54\% for specialist practice. Three quarters intended to work partly in the public sector and partly in a private capacity. London was the most popular choice of location for a post in the future. Access to a wide range of clinical work, continuing professional development, autonomy and sociability were the most important factors when considering their future choice of career.

\section{Conclusion}

Changes in the demographic profile of dental specialists and increasing opportunities for providing care within primary care may lead to difficulties in recruitment to academic and hospital posts. Increasing provision of specialist services in the 'high street' might improve access but could lead to inequalities unless these services are commissioned according to the needs of the population.

\section{IN BRIEF}

- This paper describes the changing demographic profile of dental specialists and their future career aspirations.

- Access to a wide range of clinical work, continuing professional development opportunities, autonomy and sociability were the most important factors when choosing a future career.

- Few specialists were considering an academic career in the future.

- Flexibility in the future will be key to attracting and retaining specialists to hospital and academic posts.

\section{COMMENT}

There is considerable interest in workforce planning in the dental specialties, and it is apparent that there should be a long-term strategy to meet patients' specialist dental needs. This cross-sectional survey which investigates the career aspirations of dental specialist registrars (SpRs) in the UK will help in this process. The authors are to be congratulated on obtaining a response rate of 78\%.

The increasing trend towards specialist practice is evident from the replies, with 54\% indicating this career aspiration. Although this is to be encouraged, and is in line with national policy statements, the process needs to be managed carefully to ensure an equitable distribution of specialist services across the country. This may be facilitated by the new roles envisaged for the primary care trusts after April 2005, when commissioning of dental services will occur at a local level.

It is a concern that only a fifth of SpRs indicated that they would consider an academic appointment. This is further confirmation of the likely continuation of the recruitment difficulties in academic dentistry. Such posts might become more attractive if attention was paid to the factors identified in the paper as influencing future career choice. It is perhaps not surprising that the range of clinical work came out top, but it is encouraging that access to CPD and multidisciplinary working were also highly rated as influencing future career moves.

The article also highlights the importance of an even distribution of training places throughout UK. The majority of SpRs wish to remain locally when they complete their training, although many would be prepared to move for a suitable post. Nevertheless, this finding supports the future allocation of additional SpR posts according to a weighted capitation model, taking into account the needs of the local population.

It is surprising that 21 respondents were in wholly self-funded posts and 43 were partly self-funded. This anomaly exists only in dentistry, and surely it is time to look again at this issue. Why should some SpRs have to pay for their training within the NHS clinical services? It is a requirement of all SpR posts that a clinical and didactic teaching programme is provided. Why should some individuals have to pay for their education and training?

Overall, this is an interesting paper, and is of value to the profession and healthcare planners.

Professor J. W. Frame, Postgraduate Dental Dean, West Midlands Deanery doi:10.1038/sj.bdj.4811387 